\title{
APPLICATIONS OF COMPUTER VISION IN MEASURING TOTAL CUMULATIVE PITCH DEVIATION OF A GEAR
}

\author{
Dong-yuan Ge, Xi-fan Yao, Zhao-tong Lian, Hai-zhi Wang, Tao Tao
}

Original scientific paper

As the basic part of the mechanical transmission, gears should have high transmission accuracy, so the gear's precision measurement is a key technology. Based on the existing research, the computer vision technology is introduced in gear test. According to the definitions of technical indexes, such as pitch deviation, tooth thickness deviation, etc., through analysis and research, a new measurement method is proposed, so as to complete the determination of the modulus, tooth number and total accumulated pitch deviation of a gear. In the proposed methods, those indexes such as the pitch and tooth thickness, are measured in arc length, rather than in chordal length, so that they are consistent with their definitions. And the measured points can be positioned on the reference circle of a gear while the pitch and total accumulative pitch deviations are examined. Finally, a gear is measured with the proposed method. The main test is obtained as follows. The single pitch deviation is $10,3 \mu \mathrm{m}$, total cumulative pitch deviation is $44,8 \mu \mathrm{m}$, and tooth thick deviation is 5,2 $\mu \mathrm{m}$. The experiment demonstrates that the proposed method is feasible and effective, and can meet the precision need of engineering practice. This study provides a new solution method for the gear's on-line measurement.

Keywords: computer vision; involute; reference circle; tooth thickness deviation; total cumulative pitch deviation

\section{Primjena računalnog vida u mjerenje ukupnog odstupanja zajedničkog koraka zupčanika}

Izvorni znanstveni članak

Kao osnovni dio mehaničkog prijenosa, zupčanici bi trebali imati visoku točnost prijenosa te se stoga mjerenje točnosti zupčanika smatra ključnom tehnologijom. Na temelju postojećeg istraživanja, u ispitivanje zupčanika uvodi se tehnologija računalnog vida. U skladu s definicijama tehničkih pokazatelja kao što su odstupanje koraka zupčanika, debljine zuba itd., analizom i istraživanjem se predlaže nova metoda mjerenja kako bi se upotpunilo određivanje modula, broja zubi i sveukupnog odstupanja koraka zupčanika. U predloženim metodama, pokazatelji kao što su korak i debljina zuba, mjere se radije dužinom luka nego tetivom luka, tako da budu u skladu s njihovim definicijama. Mjerene točke mogu se pozicionirati na referentnom opsegu zupčanika dok se ispituju odstupanja koraka i ukupna odstupanja zajedničkog koraka. Konačno, zupčanik se mjeri predloženom metodom. Glavni se test dobiva na sljedeći način. Odstupanje pojedinog koraka je 10,3 $\mu \mathrm{m}$, ukupno zajedničko odstupanje je 44,8 $\mu \mathrm{m}$, a odstupanje debljine zuba je $5,2 \mu \mathrm{m}$. Ispitivanje pokazuje da je predložena metoda izvediva i učinkovita i može zadovoljiti potrebe za točnošću u strojarstvu. Rad daje novo rješenje za mjerenje zupčanika on-line.

Ključne riječi: evolventan; odstupanje debljine zuba; računalni vid; referentni krug; ukupno odstupanje zajedničkog koraka

\section{Introduction}

Gear is an important rotational part of various machines, and the performance of a machine is affected by gear's precision, so decreasing gears' deviation is an inherent requirement of precision manufacturing [1]. In a straight cylindrical involute gear, there are basic parameters such as modulus $m$, tooth number $z$, pitch $p$, outside circle diameter $d_{\mathrm{a}}$, and root circle diameter $d_{\mathrm{f}}$, and so on $[2,3]$. In accordance with the national standard GB/T10095-1988 of China or a similar international standard, gear deviations include pitch accumulated deviation, gear ring radial run-out, basic tangent length change deviation, profile deviation, pitch deviation, lead deviation, tooth thickness deviation and basic tangent average deviation [2, 3]. When a gear geometry is measured, if the traditional measurement methods and tools are adopted, such as tangent micrometer, universal gear measuring instrument, and so on $[4 \div 6]$, because of the special structure of the gear, many tested parameters, there are problems such as complex operation, low efficiency, and accuracy easily influenced by human factors. In particular, as for the large size of the gear, there are difficulties in clamping and positioning. With the rapid development of computer vision technology with real time, non-touching and high automation, the computer vision and its applications become a research hotspot $[7 \div 14]$. According to the requirements of the gear's on-line detection and precision manufacturing, researchers have introduced computer vision into the measurement of gears. As such, the measurement of gears has transformed from contacting to non-contacting. Early, Zhang and Yue used computer vision to test the gear parameters [17, 18]. Chen et.al. [19] presented a dummy circle scan method to realize the inspection of micro plastic gears with computer vision. $\mathrm{Li}$ and Liu [20] obtained the center of the gear, so as to complete the measurement of straight-cut gear with keyways by improving self-adaptation filter, segmentation, edge detection, label and random Hough transform. In addition, Ling and Wang [21] proposed an error compensation model for the pitch cumulative deviation measurement, which was calculated by introducing the error compensation coefficient of the measurement position, which was converted to the reference circle of the gear. The method proposed by Ling and Wang solves the difficulty that the measuring points could not locate in the reference circle. In this study we propose a new method to detect the teeth number by comparison and XOR logic operation, which is simpler and easier to implement than that one proposed by Zhang [17] and Chen [19]. At the same time in the detection of pitch deviations, compared with the method proposed by Ling and Wang [21], it is easier to position in the reference circle, so there is no error compensation needed. On the other hand, the measured pitch is consistent with its definition, that is the measuring result is arc length rather than chordal length with conventional detection method. The research in this paper provides technical guarantee for the precision manufacturing of gears. 
The paper is organized as follows. First the current situation of gear test is introduced in Section 1. Then test method of gear parameters is proposed, which includes basic parameters and total cumulative pitch deviation and so on in the next section. In Section 3, experiment for gear measurement is carried out, where the tooth number, modulus, diameter of reference circle, total cumulative pitch deviation and tooth thickness and so on are tested. Finally, conclusions and further work on measurement of gear with advance technology are given in Section 4.

\section{Test method of gear parameters}

\subsection{Basic Parameters and test method of involute gears}

The diagram of a cylindrical involute gear is shown in Figure 1. The swelling part of the gear is called a tooth, which is arranged in a circle, and the teeth of gear pair engage with each other, which can make the gears to run continuously. The basic parameters are listed as follows.

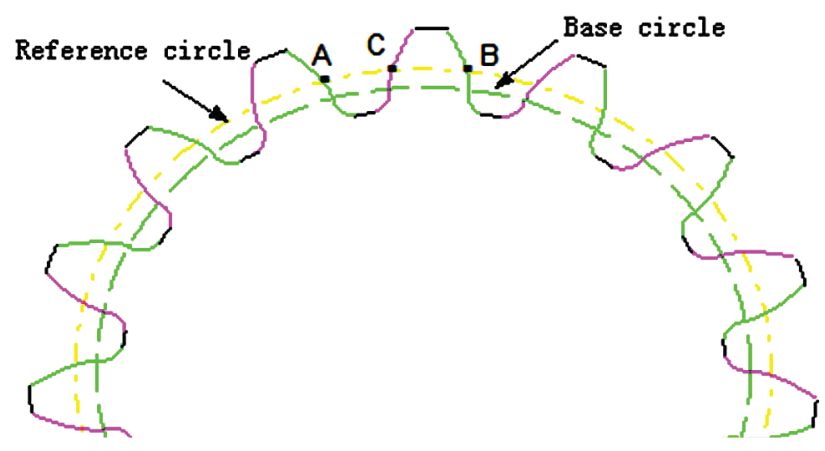

Figure 1 Frontal projection of flank profile of involute gear

(1) Number of teeth: the teeth number on the entire gear circumference, which is denoted with $z$.

The diameter of the outside circle: according to the coordinates of the outside circle the equation of the ellipse is fitted as following,

$$
A x^{2}+B x y+C y^{2}+D x+E y=1,
$$

Its center coordinates are $\left((B E-2 C D) /\left(4 A C-B^{2}\right)\right.$, $\left.(B E-2 A E) /\left(4 A C-B^{2}\right)\right)$, and the distance between the outside circle sampled points and the center is taken as radius. The outside circle's diameter is obtained from the mean of the radiuses, denoted with $d_{\mathrm{a}}$.

(2) Root circle diameter: similarly, firstly elliptical equation of root circle is fitted, so the root circle diameter is gotten according to its radius' average value, denoted with $d_{\mathrm{f}}$.

(3) Reference circle: the reference circle is a circle with standard pressure angle and the standard modulus, which is shown in Fig. 1. The diameter of the reference circle is obtained by the gear's modulus and teeth number, denoted with $d_{\mathrm{r}}$.

(4) Tooth thickness: the arc length of arc between the two sides of a gear tooth in reference circle, as is shown in Fig. 1, where the length of the arc $C B$ is tooth thickness, denoted with $s$.

(5) Space width: The width or spacing between two adjacent teeth in reference circle. As shown in Fig. 1, the length of the arc $A C$ is taken as space width, and in the reference circle of involute cylindrical gear, tooth thickness is equal to space width, that is $s=e$.

(6) Pitch: in the reference circle, minor arc length of adjacent two teeth in the same side of the tooth profile is pitch. As is shown in Fig. 1, length of the arc $A B$ is circular pitch, denoted with $p$, and $p=s+e$.

(7) Modulus: the parameter of the gear size, $m$, which is the ratio of the pitch to circumference ratio, i. e. $m=p / \pi$. If moduli of a pair of meshing gears are equal, the gears would run smoothly.

For the involute gear, the gear modulus should adhere to the standard, which can reduce the number of cutting tools and the cost of the gear processing, and at the same time improve the manufacture precision.

While the modulus of gear is determined, firstly reference circle's diameter approximate value is obtained according to the diameter of gear's outside circle and root circle. Then modulus' approximation value is gotten according to the teeth number, i. e. $m^{\prime}=\left(2 r_{\mathrm{a}}+2 r_{\mathrm{f}}\right) / z$, where the $r_{\mathrm{a}}$ and $r_{\mathrm{f}}$ are the radius of outside circle and root circle. By comparing with standard module, the closest value to standard modulus is taken to be gear's actual modulus $m$. And with modulus $m$ and tooth number $z$, the radius of the reference circle $r$ is gotten as follows,

$r=0,5 m z$,

Then the base circle's radius is obtained as the following,

$r_{b}=r \cos \alpha$

where $\alpha$ is press angle in reference circle, and in general, $\alpha=20^{\circ}$.

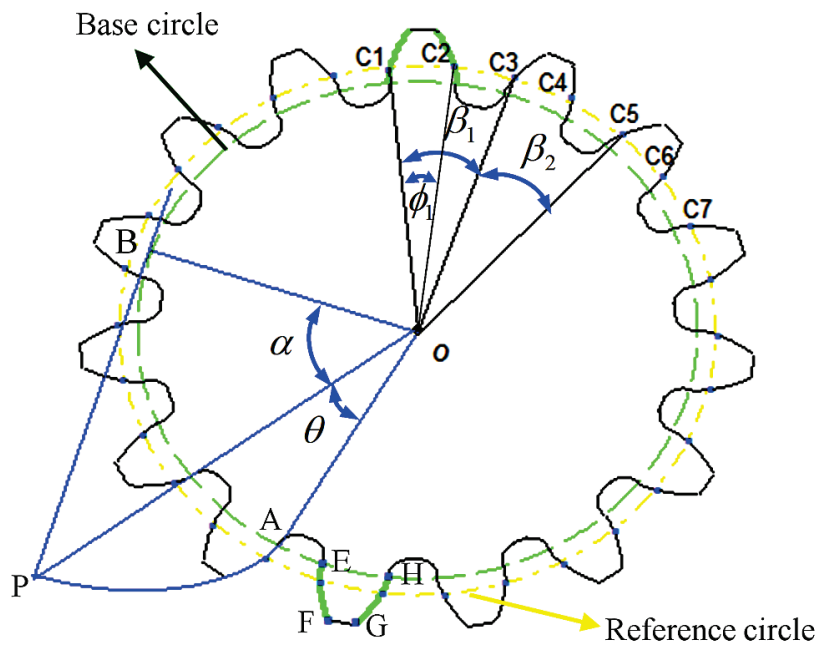

Figure 2 Standard gear diagram

\subsection{The measurement principle of the total pitch deviation}

In Fig. 2, assume the length of line oP between point $\mathrm{P}$ and the base circle center o be $r_{\mathrm{k}}$, pressure angle $\alpha$, the angle of involute exhibition $\theta$, involute rolling angle $\omega=\alpha+\theta$. If point $\mathrm{A}$ in the base circle is the starting point of the involute, and the rolling angle $\omega$ is taken as a variable, then the mathematical expression of involute is written as following, 


$$
\begin{aligned}
& \theta=\omega-\tan ^{-1} \omega, \\
& r_{\mathrm{k}}=r_{\mathrm{b}} \sqrt{1+\omega^{2}},
\end{aligned}
$$

where $r_{\mathrm{b}}$ is the radius of basic circle.

As for standard gears, the two theoretical curves of a tooth are in coincidence with its actual profile. As shown in Fig. 2, the curves EF, GH and other theoretical involutes constitute the profile of the gear.

(1) Pitch deviation $\Delta f_{\mathrm{pt}}$

The pitch deviation $\Delta f_{\mathrm{pt}}$ is the difference of the actual pitch and the theoretical pitch of a gear. If pitch deviation is in accordance with the requirements of pitch deviation, gears can move smoothly.

In engineering, it is difficult to make the measurement points be located at the reference circle accurately while the pitches are tested with traditional touching methods. Generally it is permitted that measurement points are located at the tip and middle part of the gear's profile. It is similar for the measuring of tooth thickness. If the computer vision measurement technology is adopted, through image processing and data processing for the sampled gear image, the mathematical expression of the reference circle is obtained while the outside circle, root circle and inner circle of gear are fitted. Then the intersection points of the gear profile and the reference circle are gotten, i.e. $\mathrm{c}_{1}\left(x_{1}, y_{1}\right), \mathrm{c}_{2}\left(x_{2}, y_{2}\right)$, $\mathrm{c}_{3}\left(x_{3}, y_{3}\right), \ldots \ldots, \mathrm{c}_{n}\left(x_{n}, y_{n}\right)$, as shown in Fig. 2. Assume the radius of reference circle to be $r$, the centre of circle to be $\mathrm{o}$, and the angle between $\mathrm{Oc}_{1}$ and $\mathrm{Oc}_{3}$ to be $\beta_{1}$, so the length of minor arc between $c_{1}$ and $c_{2}$ is the reference circle pitch of the gear, that is $p_{1}=r \beta_{1}$. While the acute angle $\beta_{1}$ is tested, with the normalized vector of $\boldsymbol{o c}_{1}$ and $\boldsymbol{o c _ { 3 }}$, we have their corresponding unit vectors $\boldsymbol{o c _ { 1 } ^ { \prime }}$ and $\boldsymbol{o c _ { 3 } ^ { \prime }}$, so their angle can be obtained in the light of the following formula,

$$
\beta_{1}=\cos ^{-1}\left(1-0,5\left\|\boldsymbol{o c _ { 1 } ^ { \prime }}-\boldsymbol{o c _ { 3 } ^ { \prime }}\right\|_{2}^{2}\right) \text {, }
$$

At the same time, the lengths of arcs between $c_{3}$ and $\mathrm{c}_{5}, \mathrm{c}_{5}$ and $\mathrm{c}_{7}, \mathrm{c}_{7}$ and $\mathrm{c}_{9}$, and so on, are obtained in turn, which are the gear's pitches $p_{2}, p_{3}, \ldots \ldots, p_{n}$ respectively.

The theoretical pitch of gear is obtained as follows,

$p=\pi \cdot m$,

Then the difference $\Delta f_{\mathrm{ptn}}$ between the actual pitch $p_{\mathrm{n}}$ and theoretical pitch $p$ is obtained. Let the maximum of the differences as pitch deviation $\Delta f \mathrm{pt}$ (If the measured values of all pitch deviations $\Delta f_{\text {ptn }}$ are truth value, the sum of all $\Delta f_{\mathrm{ptn}}$ of a standard gear is 0$)$.

(2). Total cumulative pitch deviation $\Delta F_{P}$
The total cumulative pitch deviation of gear $\Delta F_{P}$ is the maximum difference between the actual arc length and the corresponding theoretical value between two adjacent teeth on the reference circle. If the cumulative deviation value is consistent with the standard requirements, the accuracy of the transmission movement can be guaranteed. According to the deviation of the pitch, each pitch deviation is accumulated successively, i. e. $\Delta F_{p 1}=\Delta f_{p 1} \quad, \quad \Delta F_{p 2}=\Delta f_{p 1}+\Delta f_{p 2} \quad, \quad \ldots, \quad$ and $\Delta F_{p n}=\sum_{n=1}^{n} \Delta f_{p n}$, until the final cumulative pitch deviation $\Delta F_{p z}$ is obtained ( $z$ is the number of teeth). According to the above data, if the maximum value is $\Delta F_{p i}$ and the minimum is $\Delta F_{p j}$, the total cumulative pitch deviation $\Delta F_{p}$ can be obtained, i. e. $\Delta F_{p}=\Delta F_{p i}-\Delta F_{p j}$.

(3). Tooth thickness deviation $\Delta E_{s}$

Tooth thickness deviation is the difference of the actual thickness of tooth and its theoretical one. Its measurement is similar to that of a pitch. Firstly the crossover points of the reference circle and profile are solved, i. e. $\mathrm{c}_{1}\left(x_{1}, y_{1}\right), \mathrm{c}_{2}\left(x_{2}, y_{2}\right)$, $\mathrm{c}_{3}\left(x_{3}, y_{3}\right), \ldots . .$, and $\mathrm{c}_{n}\left(x_{n}, y_{n}\right)$. Then according to the Eq. (6), the angles between the $\mathrm{oc}_{1}$ and $\mathrm{oc}_{2}, \mathrm{oc}_{3}$ and $\mathrm{oc}_{4}$, and so on are obtained in turn, i. e. $\phi_{1}$, $\phi_{2}, \ldots \ldots$, and $\phi_{n}$. Finally corresponding arc lengths i.e. $r \phi_{1}, r \phi_{2}, \ldots \ldots$, and $r \phi_{n}$ are gotten respectively, which are the tooth thickness $s_{1}, s_{2}, \ldots \ldots$, and $s_{n}$. At the same time the theoretical tooth thickness is obtained, which is the half of the pitch, i. e. $s=\frac{p}{2}$.

The actual tooth thickness is subtracted by its theoretical value respectively, and the maximum of those differences is taken as the tooth thickness deviation $\Delta E_{s}$.

\section{Test experiment and data processing 3.1 Image Sampling and Processing}

In experiment, the measurement aparatus consists of monocular vision system, and the optical axis of camera is vertical to platform. While the gear is tested, firstly the computer vision system is calibrated, and the scale of camera is obtained, i. e. $2,5564 \times 10^{-1} \mathrm{~mm} /$ pixel [22 $\left.\div 25\right]$. In order to demonstrate the availability and feasibility of the proposed method, some known parameters of the examined gear are as follows: its tooth number is 15 , and the diameter of its inner hole is $34 \mathrm{~mm}$.

According to the proposed method, first the gear's image is sampled, as shown in Fig. 3. Then the image is processed to extract the edge feature of gear as shown in Fig. $4[26 \div 29]$. 


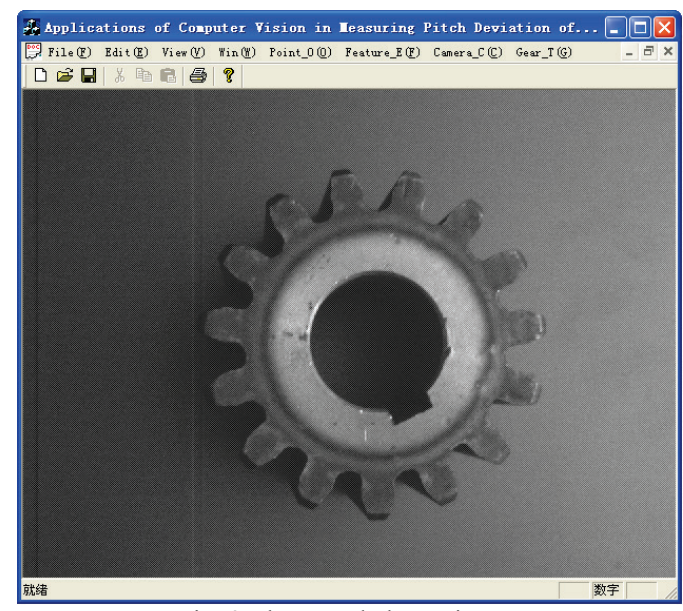

Fig. 3 The sampled gear image

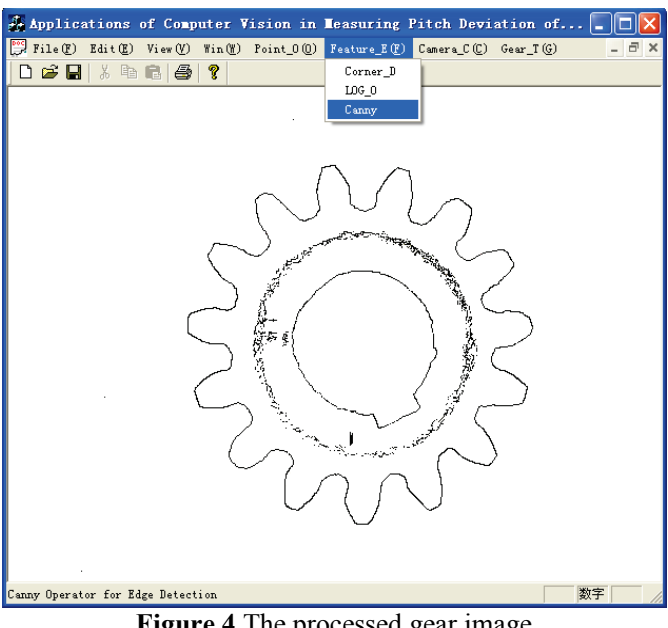

Figure 4 The processed gear image

\subsection{Basic parameters of gear measured}

According to the requirements of measuring items, the basic parameters of a gear are tested as follows.

(1) The inner hole of a gear is one of important parameters to be tested. The ellipse of the inner hole is obtained as follows,

$$
\begin{aligned}
& -6,2144 \times 10^{-6} x^{2}+1,4211 \times 10^{-7} x y-5,9614 \times 10^{-6} y^{2}+ \\
& +4,1256 \times 10^{-3} x+2,8090 \times 10^{-3} y=1
\end{aligned}
$$

The central coordinates $\left(x_{h}, y_{h}\right)$ of the inner hole obtained from Eq. (8) are $(334,6804 ; 239,5906)$. Then the distance between the central coordinates and sampled points is regarded as the radius of inner hole. Thus its diameter is obtained from the average value of radiuses, that is 133,0782 (pixel). According to the scale of CCD, the diameter is $34,0195 \mathrm{~mm}$ measured physically.

(2) Similarly the fitting equation of the outside circle is gotten as follows,

$$
\begin{aligned}
& -7,3984 \times 10^{-6} x^{2}+2,7004 \times 10^{-7} x y-6,8355 \times 10^{-6} y^{2}+ \\
& +4,8732 \times 10^{-3} x+3,1960 \times 10^{-3} y=1
\end{aligned}
$$

The central coordinates obtained from Eq. (9) are $\left(x_{a}, y_{a}\right)$ i.e. $(333,7309 ; 240,3721)$. Then the distances between the central coordinates and sampled points of outside circle are obtained. So its diameter can be obtained from the average value, that is the diameter of outside circle is 333,0409 (pixel). According to the scale of camera, the diameter is $85,1371 \mathrm{~mm}$ measured physically.

(3) The fitting equation of root circle is obtained as follows,

$$
\begin{aligned}
& -6,8687 \times 10^{-6} x^{2}+4,7849 \times 10^{-7} x y-6,4418 \times 10^{-6} y^{2}+ \\
& +4,4767 \times 10^{-3} x+2,9425 \times 10^{-3} y=1
\end{aligned}
$$

The central coordinates $\left(x_{\mathrm{f}}, y_{\mathrm{f}}\right)$ of the root circle are $(334,2670 ; 240,8104)$, obtained from Eq. (10). Similarly, the diameter of the root circle is 247,8191 (pixel) or $63,3513 \mathrm{~mm}$ physically.

In the light of the diameters of the outside and root circles, approximate value of the reference circle's radius is 145,2150 (pixel), that is $r^{\prime}=37,1221 \mathrm{~mm}$. Then the central coordinates $\left(x_{r}, y_{r}\right)$ of reference circle are obtained as $(334,2261 ; 240,2577)$, from the central coordinates of inner hole, outside circle and root circle of the gear. So the approximate equation of gear's reference circle can be written as the following,

$$
(x-334,2261)^{2}+(y-240,2577)^{2}=145,2150^{2} .
$$

Because the involute equation of a gear is transcendental, it is very difficult to solve the crossover points of the involutes and the reference circle according to the method proposed by Zhang and Chen [17, 19]. In our method, when the tooth number of gear is determined, first the distances between the sampled points of the profile and the center of the reference circle are calculated. If one front point's distance is equal to or smaller than the radius of the reference circle, and the next points' distance is equal to or larger than the radius of the reference circle, one of the sampled points, or their average value is the crossover point. Similarly, if one front point's distance is equal to or larger than the radius of the reference circle, and the next point's distance is equal to or smaller than the radius of reference circle, one of the sampled points, or their average value is the crossover point. In the algorithm, if the distance between the central coordinates of the reference circle and one sampled point is smaller than the radius of the reference circle, the counter variable is set to 0 , i. e. $i(n)=0$. If the distance between the central coordinates and the next sampled point is larger than the radius of the reference circle, and $i(n+1)=1$. Then XOR operator is carried out for the two adjacent variables. At the same time, the counter variable is accumulated, that is $k=k+i(n) \oplus i(n+1)$. (If the distance between the sampled point and central point is equal to the radius, the sampled point is the crossover point, and the accumulation operator is carried out for counter variable, that is $k=k+1)$. In experiment, when the number of tooth are tested, all the crossover points of the reference circle and the profile are solved, and the tooth number can be obtained by checking the counter variable $k$, which is 30 , so the tooth number of the gear is 15 . 


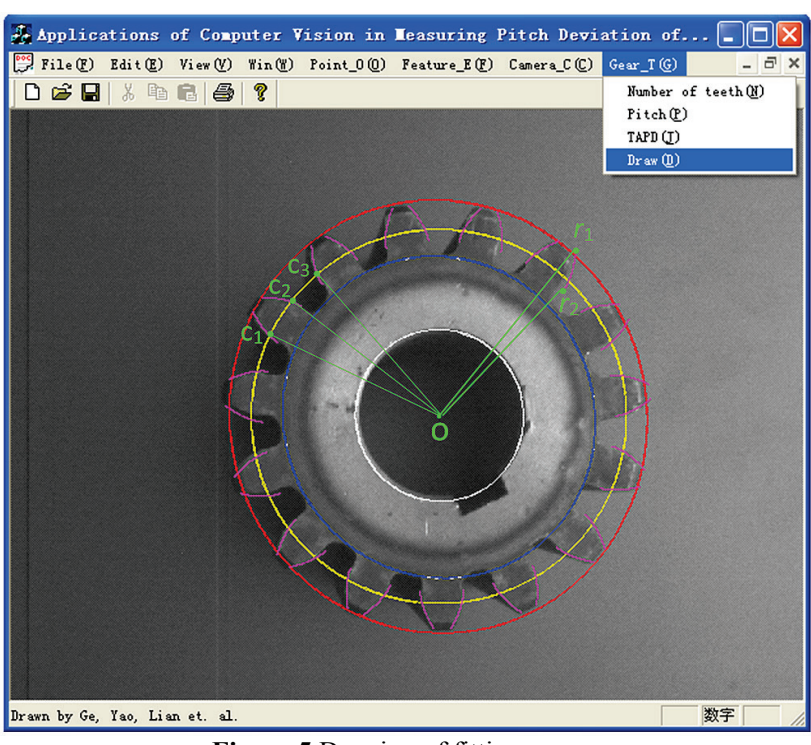

Figure 5 Drawing of fitting curves
The approximate radius of the gear's reference circle $r^{\prime}=37,1221 \mathrm{~mm}$, so the approximate modulus of the gear $m=4,9496 \mathrm{~mm}$. Then through computer programming or checking table of gear standard manuals [2, 3], the module of the gear can be obtained, i. e. $m=5 \mathrm{~mm}$. At the same time, the actual diameters of gear's reference circle can be obtained, that is $d=m z=75 \mathrm{~mm}$. According to the camera calibration parameters, the diameter is 293,3865 (pixel) in image plane.

The inner hole, outside circle, root circle and reference circle of the gear are drawn in Fig. 5 according to the Eqs. $(8) \div(11)$, where the yellow curve denotes the reference circle. (Note that the reference circle radius in the right item of Eq. (11) should be changed as 146,6933 (pixel)). At the same time, the basic parameters of the gear are listed in Tab. 1, where DIH denotes the diameter of the inner hole, DOC the diameter of outside circle, DRC the diameter of the root circle, TN the tooth number, $\mathrm{M}$ the modulus, and DRC the diameter of the reference circle.

Table 1 The measured results for the gear geometry parameters

\begin{tabular}{|c|c|c|c|c|c|c|}
\hline Method & DIH $/ \mathrm{mm}$ & DOC $/ \mathrm{mm}$ & DRC $/ \mathrm{mm}$ & $\mathrm{TN}$ & $\mathrm{M} / \mathrm{mm}$ & $\mathrm{DRC} / \mathrm{mm}$ \\
\hline The roposed method & 34,0195 & 85,1371 & 63,3513 & 15 & 5,00 \\
\hline Conventional method & 33,9854 & 85,4269 & 63,8172 & 15 & 5,00 & 75 \\
\hline
\end{tabular}

\subsection{Tooth profile computed and plotted}

While the experiments were carried out for the gear detection, the center of reference circle is taken as that of the base circle, that is $(334,2261 ; 240,2577)$. According to the Eq. (3), the basic circle's radius is 137,8466 (pixel), so one side of profile's involute expressions is rewritten as follows,

$$
\begin{aligned}
& \theta=\omega-\tan ^{-1} \omega, \\
& l=137,8466 \sqrt{1+\omega^{2}}, \\
& x_{1}=334,2261+l \cos \theta, \\
& y_{1}=240,2577+l \sin \theta .
\end{aligned}
$$

As is shown in Fig. 2, the rolling angle of the involute is $\omega$, which is the sum of the pressure angle $\alpha$ and expansion angle $\theta$. Since the starting position of the involute does not begin from the $X$ axis, the corresponding rotation angle is calculated as follows.

From Fig. 5, one of the crossover points of the base circle and the profile is $r_{1}(441,2036 ; 113,0105)$. According to computer graphics, the positive direction of the $\mathrm{Y}$ axis in image coordinate system is top-down, so we can calculate the inclination angle of the line $\mathrm{o} r_{1}, \mathrm{i}$. e. $\gamma_{1}=49,9460^{\circ}$. Then another crossover point of outside circle and profile is $r_{2}(431,4275 ; 142,6029)$. The inclination angle of the line or $r_{2}$ is obtained i.e. $\gamma_{2}=$ $45,1333^{\circ}$. So the expansion angle of the involute at the outside circle can be solved, i.e. $\theta=\gamma_{1}-\gamma_{2}=4,8127^{\circ}$. Because the involute is transcendental equation, that is $\theta=\operatorname{in} v \alpha=\tan a-a$, the pressure angle can be obtained from gear standard manuals, that is $\alpha=34^{\circ} 22^{\prime}$ $[2,3]$. From Fig. 2, $\omega=\theta+\alpha$, the rolling angle at point $\mathrm{r}_{1}$ in the outside circle is $\omega_{1}=39,1794^{\circ}$, and starting angle and end angle of the involute are 0 and $\omega_{1}$. At the same time, the involute should rotate $\gamma_{2}$ around the center of the basic circle $(334,2261 ; 240,2577)$, that is the involute should be multiplied by a rotation matrix,

$X=A x$

where $\boldsymbol{X}=\left[x_{n+1}, \quad y_{n+1}\right]^{\prime}, \boldsymbol{x}=\left[\begin{array}{ll}x_{n}, & y_{n}\end{array}\right]^{\prime}$, and $\boldsymbol{A}=\left[\begin{array}{cc}\cos \gamma_{2} & -\sin \gamma_{2} \\ \sin \gamma_{2} & \cos \gamma_{2}\end{array}\right]$

As for the other side of involute profile, according to the symmetry properties, we get it by multiplying Eq. (12) with -1 , and rotating a certain angle anticlockwise as above. In this case, it is needed to rotate an angle of $15,1517^{\circ}$ anticlockwise.

The other cogwheels can be obtained from Eqs. (12), (13), (14) and (15) by rotating angle $\beta$ around the center $(334,2261 ; 240,2577)$ of the basic circle, that is,

$\boldsymbol{X}=\boldsymbol{B} \boldsymbol{x}$,

where $\boldsymbol{X}=\left[x_{n+1}, \quad y_{n+1}\right]^{\prime}, \boldsymbol{x}=\left[\begin{array}{ll}x_{n}, & y_{n}\end{array}\right]^{\prime}$, $\boldsymbol{B}=\left[\begin{array}{cc}\cos \varphi & -\sin \varphi \\ \sin \varphi & \cos \varphi\end{array}\right]$, and $\varphi=\frac{2 \pi}{z}$.

The tooth profiles of the gear are drawn in Fig. 5 according to Eqs. (12), (13), (14), (15), (16) and (17). All the tooth profiles are plotted from the inside to the outside, they do not need being plotted precisely as those parts of the profiles near the root circle. 


\subsection{Single deviations of gears measured}

\section{Pitch deviations $\Delta E_{s}$}

First, according to the comparison and XOR logic operation, the crossover points' coordinates of gear's reference circle and profile are gotten. As can be seen from Fig. 5, with normalized processing, the unit vector $\mathrm{oc}_{1}$ and $\mathrm{oc}_{3}$ are $[0,9049 ; 0,4256]$ and $[0,6535 ; 0,7569]$ respectively. In the light of Eq. (6) we get $\beta_{1}=0,4190 \mathrm{rad}$, and the minor arc of $\overparen{c_{1} c_{3}}$ is 61,4621 pixel, so the gear's pitch $f_{\mathrm{pt1}}=15,7119 \mathrm{~mm}$. Because the theoretical pitch is $15,7080 \mathrm{~mm}$, the difference between them is taken as pitch deviation (PD), i. e. $\Delta f_{\mathrm{ptl}}=3,9 \mu \mathrm{m}$. Similarly, the other pitch deviations $\Delta f_{\text {ptn }}$ can be obtained, as shown in the second row of Tab. 2. Let the maximum of the PDs as the pitch deviation of the gear, i. e. $\Delta f_{\mathrm{pt}}=10,3 \mu \mathrm{m}$.

\section{Cumulative pitch deviation}

While the cumulative pitch deviation (CPD) is measured, in the light of all the pitch deviations of the gear, successive accumulation operator is carried out until the last pitch deviation $\Delta F_{p 15}$, that is $\Delta F_{p 1}=+3,9 \mu \mathrm{m}$, $\Delta F_{p 2}=10,3 \mu \mathrm{m}, \ldots, \Delta F_{p 10}=-6,3 \mu \mathrm{m}, \ldots$, as shown in the $3^{\text {rd }}$ row of Tab. 2 .

\section{Tooth thickness}

As can be seen from Fig. 5, while the tooth thickness is measured, first the unit vectors $\mathrm{oc}_{1}$ and $\mathrm{oc}_{2}$ are obtained, i. e. $[0,9049 ; 0,4256]$ and $[0,7966 ; 0,6045]$ respectively. We can obtain their intersection angle $\phi_{1}=$ $0,1843 \mathrm{rad}$, and the minor arc length of $\overparen{\mathrm{c}_{1} \mathrm{c}_{2}}$ is 32.8555 pixel. According to the scale of camera, the reference circle's tooth thickness of gear is $s_{1}=7,8558 \mathrm{~mm}$. Similarly, the other tooth thicknesses of the gear are obtained, which are subtracted by tooth thickness' theoretical value, the tooth thickness deviations are obtained and shown in fourth row of Tab. 2. Let the maximum of deviations as tooth thickness deviation (TTD) of the gear, that is $\Delta E_{s}=+5,2 \mu \mathrm{m}$.

Table 2 Deviations measured

\begin{tabular}{|c|c|c|c|c|c|c|c|c|c|c|c|c|c|c|c|}
\hline Tooth No. & 1 & 2 & 3 & 4 & 5 & 6 & 7 & 8 & 9 & 10 & 11 & 12 & 13 & 14 & 15 \\
\hline $\mathrm{PD} / \mu \mathrm{m}$ & $+3,9$ & $+6,4$ & $+10,3$ & $+9,7$ & $-2,6$ & $-4,8$ & $-7,2$ & $-10,3$ & $-8,1$ & $-3,6$ & $-3,9$ & $-4,3$ & $+7,8$ & $+4,2$ & $+2,3$ \\
\hline $\mathrm{CPD} / \mu \mathrm{m}$ & $+3,9$ & $+10,3$ & $+20,6$ & $+30,3$ & $+27,7$ & $+22,9$ & $+15,7$ & $+5,4$ & $-2,7$ & $-6,3$ & $-10,2$ & $-14,5$ & $-6,7$ & $-2,5$ & $-0,2$ \\
\hline $\mathrm{TDT} / \mu \mathrm{m}$ & $+1,8$ & $+3,1$ & $+5,2$ & $+4,8$ & $-1,3$ & $-2,4$ & $-3,7$ & $-5,1$ & $-4,0$ & $-1,8$ & $-1,9$ & $-2,1$ & $+3,9$ & $+2,1$ & $+1,1$ \\
\hline
\end{tabular}

In the experiment, according to Tab. 2, the pitch deviation, tool cumulative pitch deviation and tooth thickness deviation are obtained and shown in Tab. 3, where TCPD denotes the total cumulative pitch deviation. In order to compare the proposed measurement method with conventional methods, the gear is tested in universal tool microscope, and the corresponding deviations are obtained as in the $3^{\text {rd }}$ column in Tab. 3 .

Table 3 Deviations comparison

\begin{tabular}{|c|c|c|}
\hline Deviation & Proposed method & Conventional method \\
\hline $\mathrm{PD} / \mu \mathrm{m}$ & $+10,3$ & $+10,9$ \\
\hline $\mathrm{TCPD} / \mu \mathrm{m}$ & 44,8 & 45,1 \\
\hline $\mathrm{TTD} / \mu \mathrm{m}$ & $+5,2$ & $+5,2$ \\
\hline
\end{tabular}

\section{Conclusions}

This study has investigated a new method for measuring the basic parameters of involute spur gears and several individual deviations based on computer vision. Experiments demonstrate that the proposed method has the advantages of convenient operation, high efficiency and high measurement accuracy, and the measurement accuracy can meet the needs of engineering practice. If the traditional contacting method is used to measure the pitch of gear, it is very difficult to have the measurement points located at the reference circle accurately, and the resulted chordal pitch and chordal tooth thickness are not consistent with their definitions. In general, the proposed scheme is of good reference value and application value. As for the other parts of the single deviations detection, because of the limitation of computer vision and the complex structure of gear itself, it also needs to be studied further. In order to achieve the measurement of the whole single parameters and comprehensive parameters of the gear with computer vision, we need to study the characteristics of the computer vision and the technical indexes of gears in future [30, 31], so as to have new discovery and insights.

\section{Acknowledgements}

The work described in this paper is partially supported by the National Natural Science Foundation of China under grant Nos. 51675186 and 51175187, the Guangxi Natural Science Foundation under grant No. 2016GXNSFAA380111, and the Science \& Technology Foundation of Guangdong Province under grant No. 2015A020220004. The authors also gratefully acknowledge the suggestions of the reviewers, which helped to improve the presentation.

\section{References}

[1] Uematsu, Seizo; Lyu, Sung-ki; Houser, D. R.; Lim, JuSuck; Lu, Long. A Study on Reducing the Gear Tooth Profile Error by Finish Roll Forming. // Proc. of the ASME. $9^{\text {th }}$ International Power Transmission and Gearing Conference. Vol. 4, (2003), pp. 467-472. DOl: 10.1115/DETC2003/PTG-48059

[2] Cheng, Da-xian. Handbook of Mechanical Design (Fifth Edition). // Beijing: Chemical Industry Press. Vol. 3, Chapter: 14, (2008), pp. 3-21.

[3] Wen, Bang-chun. Modern Mechanical Design Handbook

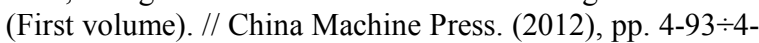
218.

[4] Dai, Juan. Application of Computer on the Experiment of Interchangeability of Technical Measurement. // Journal of Kunming University of Science and Technology. 21, 4(1996), pp. 131-136. 
[5] Ma, Yong; Wang, Kuo; Wang, Li Ding. Measuring Apparatus and Technology for Master Gears. // 2006 International Technology and Innovation Conference. (2006), pp. 353-357. DOI: 10.1049/cp:20060784

[6] Huang, Fugui; Zhang, Rencheng. Precise Measuring for Error of Tooth Form of Involute Spur Gear in 3D Coordinate Measuring Machine. // Tools Technology. 39, 7(2005), pp. 85-87.

[7] Ma, Song-de; Zhang, Zheng-you. Computer Vision-Computational theory and Algorithm Base. // Beijing: Scientific Press. (1998), pp. 1-116. DOI: 10.1109/34.888718

[8] Lin, C.; Zeng, D.; Zhao, X. L.; Cao, X. J. Numerical Calculation of Tooth Profile of a Non-circular Curved Face Gear. // Strojniski vestnik - Journal of Mechanical Engineering. 61, 5(2015), pp. 303-310. DOI: 10.5545/svjme.2014.2340

[9] Klancnik, S.; Ficko, M.; Balic, J.; Pahole, I. Computer Vision-Based Approach to End Mill Tool Monitoring. // International Journal of Simulation Modelling. 14, 4(2015), pp. 571-583. DOI: 10.2507/IJSIMM14(4)1.301

[10] Simunovic, G.; Svalina, I.; Simunovic, K.; Saric, T.; Havrlisan, S.; Vukelic, D. Surface roughness assessing based on digital image features. // Advances in Production Engineering \& Management. 11, 2(2016), pp. 93-104. DOI: 10.14743/apem2016.2.212

[11] Zhang, Zheng-you. A flexible new technique for camera calibration. // IEEE Transactions on Pattern Analysis and Machine Intelligence. 22, 11(2000), pp. 1330-1334.

[12] Wang, DZ; Mottershead, JE. Measurement Precision and Spatial Resolution with Kriging Digital Image Correlation. // Strojniski vestnik - Journal of Mechanical Engineering. 62, 7-8(2016), pp. 419-429. DOI: 10.5545/sv-jme.2016.3736

[13] Li X. Y.; Wang N. N.; Lv Y. G.; Zeng Q. L.; Hidenori K. Tooth Profile Modification and Simulation Analysis of Involute Spur Gear. // International Journal of Simulation Modelling. 15, 4(2016), pp. 649-662. DOI: 10.2507/IJSIMM15(4)6.358

[14] Ge, Dong-yuan; Xifan, Yao; Qing, Zhang. Development of Machine Vision System Based on BP Neural Network Selflearning. // 2008 International Conference on Computer Science and Information Technology. (2008), pp. 632-636. DOI: 10.1109/ICCSIT.2008.190

[15] Wang, Tong-Xiang. Research on the Measuring Instrument for Radical Composite Deviations of High-Precision Master Gears. // Dalian: Dalian University of Technology. (2010), pp. 29-56.

[16] Liu, Bin. Research on Realization method of Pitch Accuracy of Ultra-precision Master Gear. // Dalian: Dalian University of Technology. (2009), pp. 15-55.

[17] Zhang, Shao-jun; Gou, Zhong-kui; Li, Qing-li et al. Digital Image Processing Technology for Spur Gear Measurement. // Optics and Precision Engineering. 12, 6(2004), pp. 619. 625.

[18] Yue, Wei-hong. The Application Researches of Computer Vision Technology in Gear Measurement. // Wuhan: Wuhan University of Technology. (2005), pp. 71-90.

[19] Chen, Lianqing; Gao, Liguo; Shi, Yongjie; Li, Bolan. Research on the On-line Inspection of Micro Plastic Gear Based on Computer Vision. // China Mechanical Engineering. 18, 13(2007), pp. 1535-1539.

[20] Li, Peng; Liu, Qihong. Dimension Measurement of Straight-Cut Gear Based on Machine Vision. // Computer Measurement and Control. 17, 4(2009), pp. 646-648.

[21] Ling, Siying; Wang, Liding; Lou, Zhifeng; Liu, Qiang et al. Error compensation of the measurement position in ultraprecision gear pitch deviation measurement. // Chinese Journal of Scientific Instrument. 35, 3(2014), pp. 691-696.

[22] Fan, Shuo. Research on Measuring Technology of Ultraprecision Gear Total Cumulative Pitch Error. // Dalian: Dalian University of Technology. (2005), pp. 38-65.
[23] Dong-yuan, Ge; Xi-fan, Yao; Chao, Hu; Zhao-tong, Lian. Nonlinear camera model calibrated by neural network and adaptive genetic-annealing algorithm. // Journal of Intelligent and Fuzzy Systems. 27, 5(2014), pp. 2243-2255. DOI: $10.3233 /$ IFS-141188

[24] Hui, Fan; Jie, Guo; JinJiang, Li. Patchnet-Based Background Subtraction Algorithm for Dynamic Scenes Video. // ICIC Express Letters. 9, 4(2015), pp. 1101-1107.

[25] Liu, Changan; Zhan, Sheng; Wu, Hua; Dong, Ruifang. A Flying Robot Localization Method Based on Multi-sensor Fusion. // International Journal of Advanced Robotic Systems. 11, (2014), pp. 1-13. DOI: 10.5772/58927

[26] Canny, J. A Computational Approach to Edge Detection. // IEEE Transactions on Analysis and Machine Intelligence. 8, 6(1986), pp. 679-698. DOI: 10.1109/TPAMI.1986.4767851

[27] Qian, Wenhua; Xu, Dan; Yue, Kun; Guan, Zheng. Image Abstraction Painting of Flow-like Stylization. // Tehnički Vjesnik - Technical Gazette. 22, 4(2015), pp. 837-844. DOI: 10.17559/TV-20150612175259

[28] Fitri, Utaminingrum; Keiichi, Uchimura; Gou, Koutaki. Mixed Gaussian and Impulse Noise Removal Based on Kernel Observation and Edge Direction. // International Journal of Innovative Computing, Information and Control. 11, 5(2015), pp. 1509-1523.

[29] Marek, Magdziak. An Algorithm of Form Deviation Calculation in Coordinate Measurements of Free-Form Surfaces of Products. // Strojniški vestnik - Journal of Mechanical Engineering. 62, 1(2016), pp. 51-59. DOl: 10.5545/sv-jme.2015.3039

[30] Wilbur, Larson. Gearing Errors as Related to Alignment Techniques of the Rotary-Vane Attenuator. // IEEE Transactions on Instrumentation and Measurement. Vol. IM-14, 3(1961), pp. 117-123.

[31] Ryu, D.; Dong, B.; Davidson, T.; Burton, A.; Um, D. Model-based Micro Profile Measurement using Multifocused Images for Micro Gear Assembly. // Proceedings of the $5^{\text {th }}$ IEEE International Conference on Nano/Micro Engineered and Molecular Systems. (2010), pp. 844-849. 


\section{Authors' addresses}

Dong-yuan Ge, Associate Professor, Ph. D.

(Corresponding author)

1) School of Mechanical Engineering, Guangxi University of

Science and Technology, No. 268, East Central Avenue,

Chengzhong Distract, Liuzhou city, Guangxi Prov., China, 545006

2) Faculty of Business Administration, University of Macau,

Av. Padre Tomás Pereira Taipa, Macau SAR, P. R. China

E-mail: gordon399@163.com

\section{Xi-fan Yao, Profesor}

School of Mechanical and Automotive Engineering, South China University of Technology, No. 381, Wushan Rd., Tianhe Dist.,

Guangzhou, Guangdong Prov., 510640, P. R. China

E-mail: mexfyao@scut.edu.cn

\section{Zhao-tong Lian, Profesor}

Faculty of Business Administration, University of Macau,

Av. Padre Tomás Pereira Taipa, Macau SAR, P. R. China

E-mail: lianzt@umac.mo

\section{Hai-zhi Wang, Lecturer}

School of Marine Engineering, Jimei University,

No. 185, Yinjiang Rd., Jimei District, Xiamen City, Fujian Prov.

361021, P.R. China.

Email: 81984446@qq.com

\section{Tao Tao}

School of Mechanical and Automotive Engineering, South China University of Technology, No. 381, Wushan Rd., Tianhe Dist.,

Guangzhou, Guangdong Prov., 510640, P. R. China

E-mail: 310266638@qq.com/harry1992@vip.qq.com 